\title{
ELECTRO PNEUMATIC CONTROL SYSTEM FOR INVERTED PENDULUM
}

\author{
Krzysztof POPŁAWSKI," Leszek AMBROZIAK, ${ }^{*}$ Mirosław KONDRATIUK \\ *Bialystok University of Technology, Faculty of Mechanical Engineering, Department of Robotics and Mechatronics, \\ ul. Wiejska 45C, 15-351 Białystok, Poland \\ r.c.drifter.d1@gmail.com, l.ambroziak@pb.edu.pl, m.kondratiuk@pb.edu.pl
}

received 1 March 2020, revised 30 May 2020, accepted 4 June 2020

\begin{abstract}
The paper concerns the inverted pendulum control system with using pneumatic cylinder. A mathematical model of the pendulum used to derive the LQG controller was presented. Prepared laboratory stand was presented and described in detail. The main purpose of the work was experimental researches. A number of control process tests were conducted with variable model parameters such as additional mass, injected disturbances and so on. The results were shown on the time plots of the control object states.
\end{abstract}

Keywords: Inverted pendulum, pneumatic actuator, inverted pendulum control, encoder, stabilization

\section{INTRODUCTION}

Inverted pendulums are popular systems used in researches about control theory. Nowadays, there are many configurations of inverted pendulums. The most common pendulums are linear, rotational (Ahangar-Asr et al., 2011), (Ozbek et al., 2010), single (Astrom et al., 2000), double (Sang et al., 2011) or triple (Zhangn et al., 2017) and pendulums on a cart (Hui et al., 2016). Many analyses on inverted pendulums are conducted because of similarity to such objects as robots and rockets (Boubaker, 2012), (Hovingh et al., 2007). These analysis mostly concerned with modern control systems application like genetic adaptive (Moore et al., 2001), with visual feedback (Wang et al., 2008) or another advanced control methods (Zhijun et al., 2013) including sliding mode control and swing up control. There are also investigations concern nonlinear analysis (Boubaker, 2013), (Prasad et al., 2013). Moreover, the actuation systems for inverted pendulums were intensively studied. We can list here the electric, pneumatic or hydraulic drives applied to pendulum stabilization (White et al., 1999).

Controlling an inverted pendulum on a cart requires knowledge on implementing algorithms by means of digital devices and pneumatically actuated systems (Uszynski, 2018). Control systems based on PC stations and separate signal processing cards are very often used. Inverted pendulum systems can be controlled with different types of drives. Pneumatic actuators are not very popular, mainly because of air compressibility and significant mechanical friction (Beater, 2007). On the other hand, high durability and simple maintenance makes pneumatic drives a good replacement for electric drives.

This paper presents design and construction of inverted pendulum system controlled with pneumatic actuator and Arduino Due microcontroller. Second chapter presents the development of cart position and pendulum angle measurement system. In this part, an optical encoder was designed. Computer program that measures pendulum angle was implemented by means of Arduino microcontroller and Simulink environment. In order to define the cart position, a linear potentiometer with analogue output was used. Third chapter presents a design of inverted pendulum control system and output signal amplifier. Next chapter describes the derivation of inverted pendulum mathematical model, which was used to predefine linear-quadratic regulator and Kalman state observer. Design of pneumatically actuated inverted pendulum was developed by means of CAD software. In chapter five, experimental setup and research results in the form of plots (pendulum angle, cart position and control signal) were presented.

\section{MEASUREMENT OF CART POSITION AND INVERTED PENDULUM ANGLE}

Design and practical implementation of the inverted pendulum system is connected with two main tasks. First is the measurement of the pendulum deflection angle and the second is reading cart position.

\subsection{Pendulum angle measuring system design}

Optical encoders can be used to measure linear or rotational movement. Generally, we can divide them into two types: incremental or absolute encoders. The main difference between them is the possibility to remember the position after loss of power. Incremental encoder only sends electric pulses - that is why, during every single turning on, the device has to calibrate its position. This drawback can lead into loss of pulses and false position measurement. Absolute encoders use Gray code to define the position and need more optical sensors. This makes them more complicated and more expensive.

To measure the rotation of inverted pendulum, it would be easier to buy an absolute encoder but to reduce cost of made it, an incremental encoder from ink printer was used. The inconvenience will be the need to use the pendulum position calibration, but some software modifications can allow to do it even on running program in microcontroller. The used optical encoder AEDS- 
962x (Fig. 1) from Avago Technologies does not require to amplify pulses (Avago, 2006).

It is equipped with two output channels, and thanks to this feature, it is possible to distinguish the direction of pendulum rotation. Microcontroller Arduino Due has a pin that can be used as a $3.3 \mathrm{~V}$ power supply for encoder. Each pulse on both channels is detected by means of external interrupts on microcontroller digital inputs. This function guarantees that no pulses will be lost and also that computing power is not harmed.

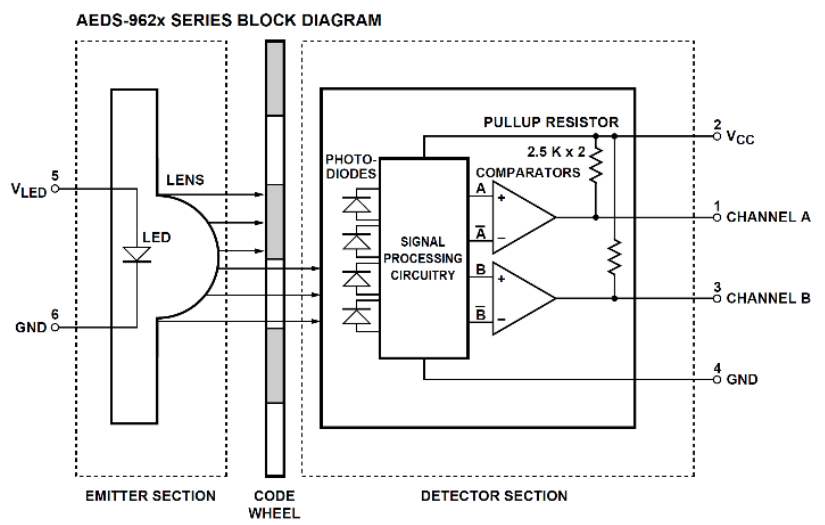

Fig. 1. Optical encoder block diagram (Avago, 2006)

The programming part of the project was realized in MATLAB/Simulink environment (MathWorks, 2017). Creating the program is quite intuitive and Arduino products are supported, but to measure the pendulum angle, a special function in the form of a block had to be developed. This process starts from empty 'SFunction Builder' block that can contain specified parts of $\mathrm{C}$ code. Choosing open source library for optical encoders reduced amount of code and complexity of configuration 'S-Function Builder' block. Using external interrupts on both optical encoder channels and high resolution disk resulted in reading pendulum angle by every $0.08^{\circ}$.

\subsection{Reading cart position with linear potentiometer}

Another necessary variable that had to be measured was linear cart position. Pneumatic system is based on Festo products. That is a way in which a linear encoder MLO-POT-TLF was used. This encoder has one 0-10 V range analogue output. Arduino Due has limited maximal voltage to $3.3 \mathrm{~V}$; therefore, simple voltage divider based on two resistors was made. Each resistance was calculated from simple equation (1) written below:

$U_{\text {out }}=\frac{R_{2}}{R_{1}+R_{2}} \cdot U_{\text {in }}$

Reading cart position in Simulink is simpler since there is ready 'Analog Input' block that has two configurable parameters: pin number and sampling time. Pendulum and cart positions can be analysed in real time using 'Time Scope' block.

\section{INVERTED PENDULUM CONTROL SYSTEM DESIGN}

Electro pneumatic diagram (Fig. 2) was developed in FluidSIM software. The system consists of air preparation unit $(0.1)$, rodless cylinder (1.0) and proportional directional control valve (1.2).

Depending on the control voltage applied to the proportional valve, its position can change. Spool position determines the speed and direction of the cylinder slider movement. Prechosen Festo DGPL cylinder has a very solid slider that allows to make simple and easily mounted construction with pendulum.
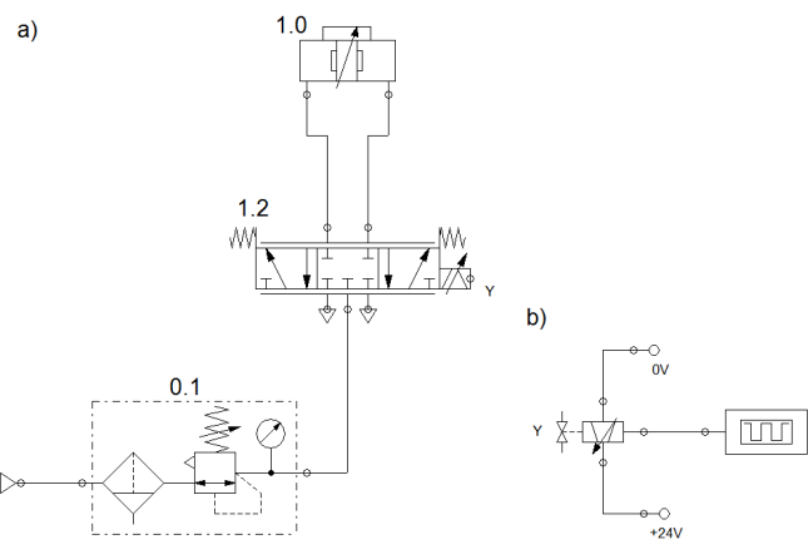

Fig. 2. Electro pneumatic system: a) pneumatic part, b) electrical part

The proportional valve MPYE-5 can be controlled with $0-10 \mathrm{~V}$ range analogue signal. Arduino Due has two analogue output pins but they are not standardized with industrial devices. These outputs have a range from $0.55 \mathrm{~V}$ to $2.75 \mathrm{~V}$ and 12-bit DAC converter. In order to achieve $0-10 \mathrm{~V}$ control signal, a simple differential amplifier was realized. Using an operational amplifier allowed to remove the $0.55 \mathrm{~V}$ offset and amplify the output signal in order to reach the desired value. Fig. 3 shows the diagram of the circuit.

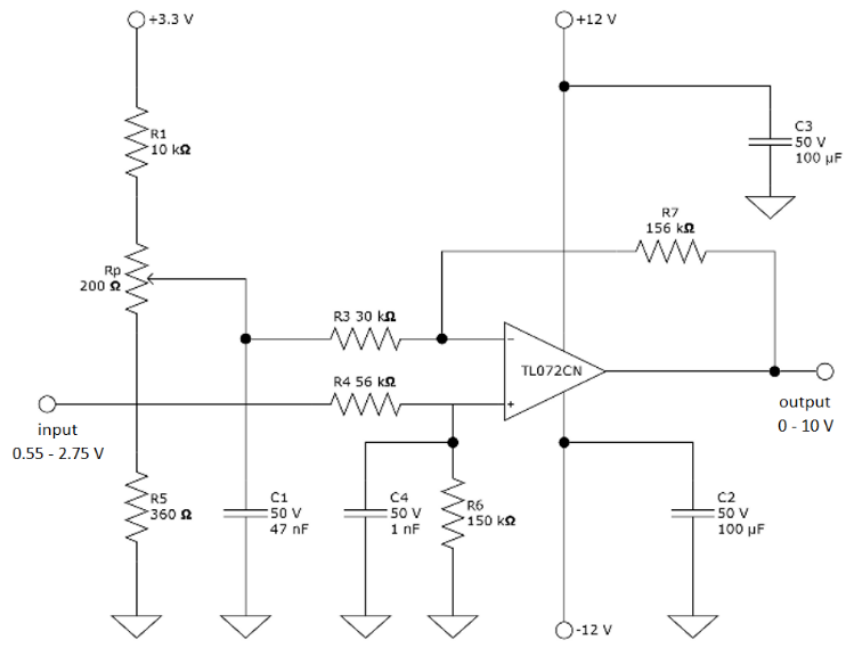

Fig. 3. Differential amplifier circuit diagram

The amplifier is based on integrated circuit TL072CN, which has to be supplied with symmetrical voltage. This small drawback also has a good effect because only this kind of amplifiers can reach exact $0 \mathrm{~V}$ in this application. Resistor $\mathrm{R} 4$ makes sure that current on Arduino output is limited and capacitor C4 reduces eventual possibility of noises in the signal.

The prepared electrical circuit was specifically developed in the form of a PCB (printed circuit board) using thermal transfer 
method. Fig. 4 presents the final effect of the circuit that consisted of the amplifying part and additional four voltage dividers adjusted for sensors with 0-10 V output signals.

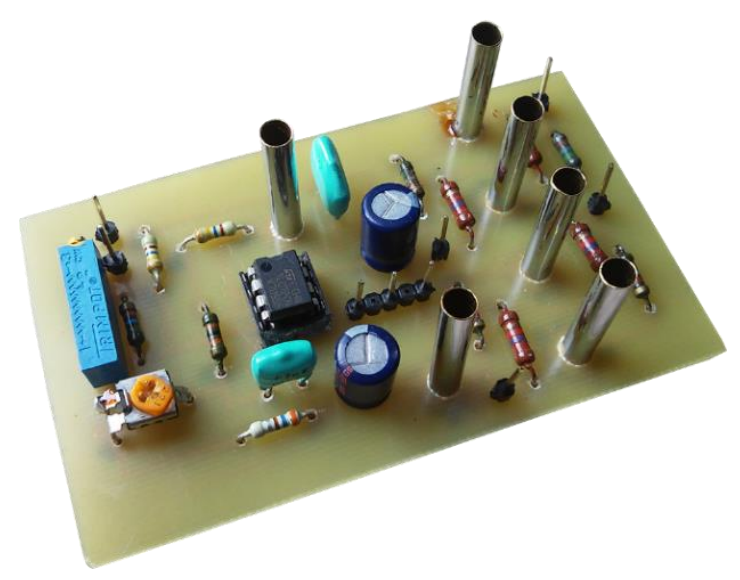

Fig. 4. Developed control signal amplifier and voltage dividers

Controlling analogue output in Simulink is similar to reading signals. This can be done with one already provided block that has one configurable parameter, which is DAC pin number. In order to be able to control, the proportional valve signal had to be biased to $5 \mathrm{~V}$ (valve closed position) and limited to $0-10 \mathrm{~V}$ range.

\section{INVERTED PENDULUM MODEL AND CONTROLLER DE- SIGN}

Fig. 5 presents the physical model of the inverted pendulum where: $\mathrm{M}$ - cart mass [kg], $\mathrm{m}$ - pendulum mass [kg], $\mathrm{b}$ - damping coefficient in linear motion [N.s/m], $b_{p}$ - damping coefficient in rotational motion [N.s/rad], I - pendulum mass moment of inertia $\left[\mathrm{kg} \cdot \mathrm{m}^{2}\right], \mathrm{x}$ - cart coordinate $[\mathrm{m}], \theta$ - pendulum deflection angle [rad], I - pendulum half-length [m], g - acceleration of gravity $\left[\mathrm{m} / \mathrm{s}^{2}\right], \mathrm{F}$ - cylinder applied force $[\mathrm{N}]$.

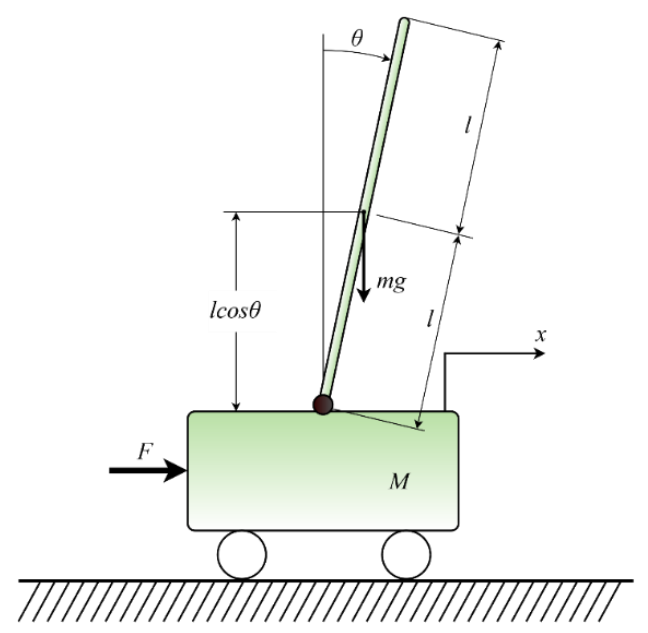

Fig. 5. Physical model of inverted pendulum

It is an unstable system in vertical pendulum position that can rotate freely in one plane. Applying force $F$ to the cart allows to control the pendulum position.

After the calculation of forces in the inverted pendulum, the system of nonlinear equations (2) and (3) was obtained:

$(M+m) \ddot{x}+b \dot{x}+m l \ddot{\theta} \cos \theta-m l \dot{\theta}^{2} \sin \theta=F$

$\left(I+m l^{2}\right) \ddot{\theta}+m l \ddot{x} \cos \theta=m g l \sin \theta-b_{p} \dot{\theta}$

In order to linearize these equations, a model operating point was assumed in the top pendulum position. Assuming small angle deflections, we have the approximations: $\sin \theta \approx \theta, \cos \theta \approx 1$, $\dot{\theta}^{2} \approx 0$. Now linearized equations can be described with equation (4) and (5):

$$
\begin{aligned}
& (M+m) \ddot{x}+b \dot{x}+m l \ddot{\theta}=F \\
& \left(I+m l^{2}\right) \ddot{\theta}+m l \ddot{x}+b_{p} \dot{\theta}=m g l \theta
\end{aligned}
$$

Based on the above equations, we can have the following state-space model described with following equations:

$\dot{\mathbf{x}}=\mathbf{A x}+\mathbf{B u}$,

$\mathbf{y}=\mathbf{C x}+\mathbf{D u}$,

where:

$\mathbf{x}=\left[\begin{array}{l}x_{1} \\ x_{2} \\ x_{3} \\ x_{4}\end{array}\right]=\left[\begin{array}{c}\theta \\ \dot{\theta} \\ x \\ \dot{x}\end{array}\right]$,

$\mathbf{A}=\left[\begin{array}{cccc}0 & 1 & 0 & 0 \\ \frac{(M+m) m g l}{q_{1}} & \frac{-(M+m) b_{p}}{q_{1}} & 0 & \frac{m l b}{q_{1}} \\ 0 & 0 & 0 & 1 \\ \frac{m l b}{q_{1}} & \frac{m l b_{p}}{q_{1}} & 0 & \frac{-\left(I+m l^{2}\right) b}{q_{1}}\end{array}\right]$

$\mathbf{B}=\left[\begin{array}{c}0 \\ \frac{-m l}{q_{1}} \\ 0 \\ \frac{\left(I+m l^{2}\right)}{q_{1}}\end{array}\right]$,

$\mathbf{C}=\left[\begin{array}{llll}1 & 0 & 0 & 0 \\ 0 & 0 & 1 & 0\end{array}\right]$

$\mathbf{D}=\left[\begin{array}{l}0 \\ 0\end{array}\right]$,

and $q_{1}=(M+m) I+M m l^{2}$.

For stabilizing inverted pendulum system dynamics, the LQR (Linear-Quadratic-Regulator) controller was developed and implemented to ensure local stability of the control plant. LQR approach is often used and mentioned to stabilize a structurally unstable system like inverted pendulum. LQR controller uses measurements $\mathbf{y}$ of control plant to generate a control signal $\mathbf{u}$ that controls $y$. The LQR regulator minimizes the cost function:

$J=\int_{0}^{\infty}[\mathbf{x}(t) \mathbf{Q x}(t)+\mathbf{u}(t) \mathbf{R u}(t)] d t$

The state control law we can be written as follows:

$\mathbf{u}=-\mathbf{k x}$

The closed loop system can be determined with equation (9) as:

$\dot{\mathbf{x}}=[\mathbf{A}-\mathbf{B k}] \mathbf{x}$

In addition to the state-feedback gain $\mathbf{k}, \mathrm{LQR}$ returns the solution $\mathbf{S}$ of the associated Riccati equation described as: 
$\mathbf{A}^{\mathrm{T}} \mathbf{S}+\mathbf{S A}-\mathbf{S B R}^{-\mathbf{1}} \mathbf{B}^{\mathrm{T}} \mathbf{S}+\mathbf{Q}=\mathbf{0}$

where $\mathbf{k}$ is derived from $\mathbf{S}$ using following formula:

$\mathbf{k}=\mathbf{R}^{-1} \mathbf{B}^{\mathrm{T}} \mathbf{S}$

In order to determine $\mathbf{Q}$ and $\mathbf{R}$ values, Bryson's rule was used.

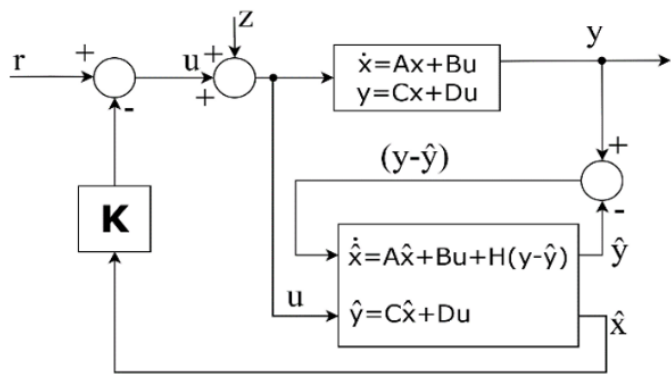

Fig. 6. Implemented control system

During the experimental setup, we cannot measure all the state vector elements. That is why, we have to estimate them. In this purpose, a state observer was designed. During this process, it is important to place poles on the left from the observed system poles. Combining LQR regulator and Kalman filter resulted in obtaining the final control algorithm for inverted pendulum system called LQG (Bryson et al., 1969). Fig. 6 presents control system.

Simulation results are presented in Fig. 7. Initially, the pendulum is deflected $3^{\circ}$ from the vertical position and at the seventh second, an external disturbance force $(100 \mathrm{~N})$ is applied in order to check the control system robustness.
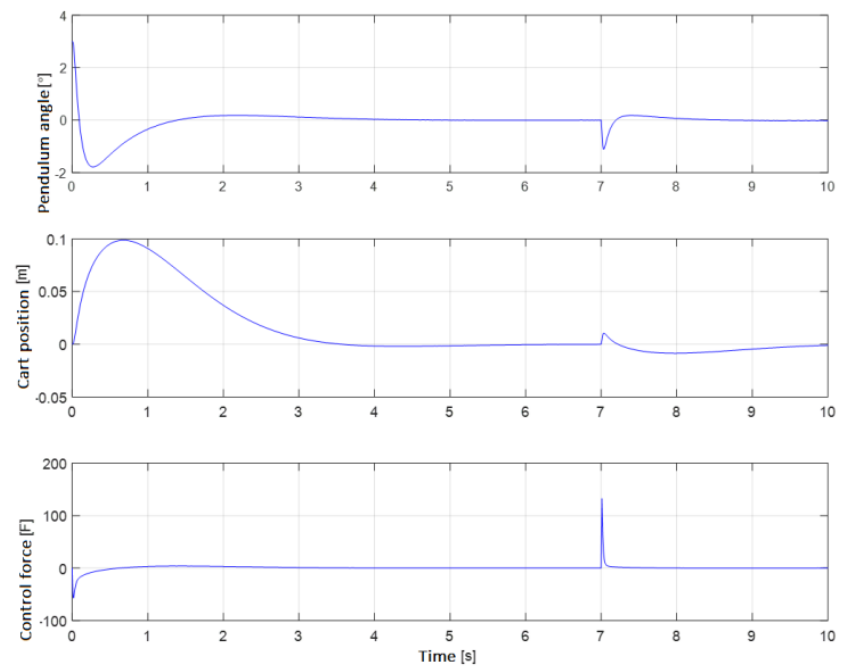

Fig. 7. Simulation results in form of a plots

Achieved results do not exceed the predicted values, which means - in this way, the control design can be considered successful.

\section{EXPERIMENTAL SETUP AND RESULTS}

Experimental setup is presented in Fig. 8 consists of: 1 - air compressor, 2 - air preparation unit, 3 - directional proportional control valve, 4 - rodless cylinder, 5 - linear potentiometer, 6 - optical encoder, 7 - inverted pendulum module, 8 - external power supply, 9 - signal amplifier, 10 - microcontroller, 11 - PC station.

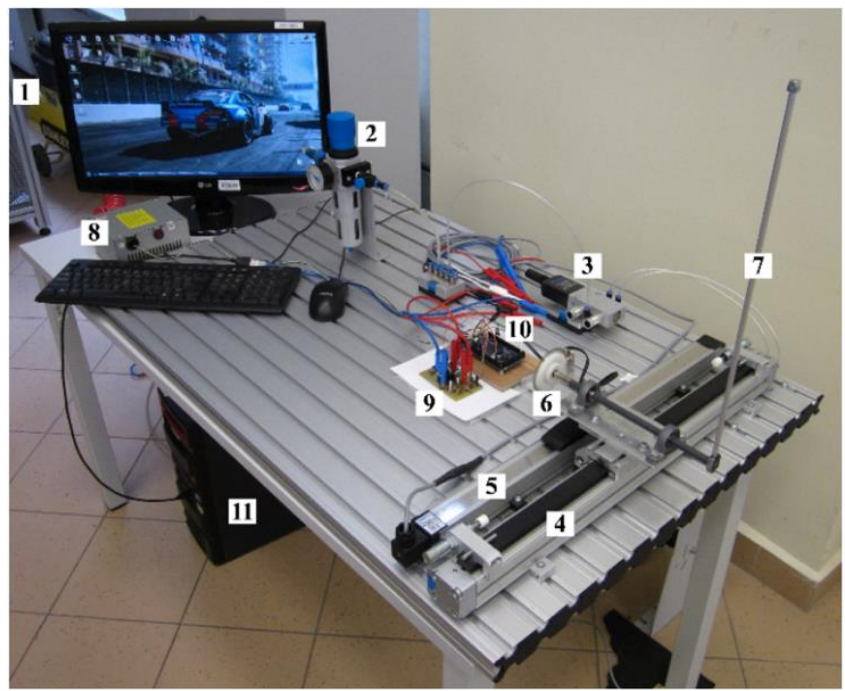

Fig. 8. Experimental setup of pneumatically actuated inverted pendulum system

All the elements are also included in the diagram in Fig. 9.

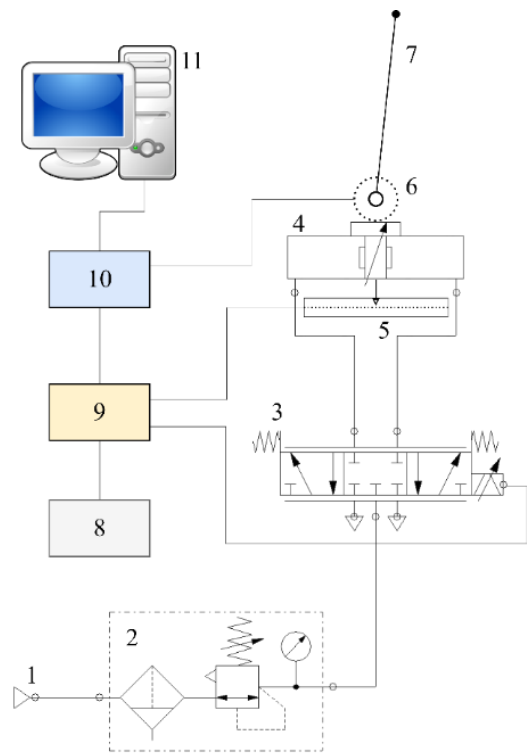

Fig. 9. Experimental system diagram

Serial transmission between PC and microcontroller allows to draw plots, save data and change online parameters during the experiment. Arduino Due can also be programmed as an independent device to stabilize the inverted pendulum, but then there is no interface to interact in such a mode.

During the experiment, the developed inverted pendulum system was tested with external disturbances in the form of a push and step change of set cart position. Each experiment was conducted at full air compressor tank at $0.8 \mathrm{MPa}$. Then the air pressure was reduced to $0.5 \mathrm{MPa}$.

In Fig. 11-14, the system responses for external disturbance are presented. After the disturbance, the cart is moving in order to stabilize the pendulum. Oscillations on the plots are the result of significant static friction during linear cylinder movement. Inverted 
pendulum system needs about 3 seconds to reach a stable position, maximal deflection angle was around $3^{\circ}$ and the cart had to travel approximately $80 \mathrm{~mm}$. Control signal amplitude is fading as pendulum is reaching a stable position.

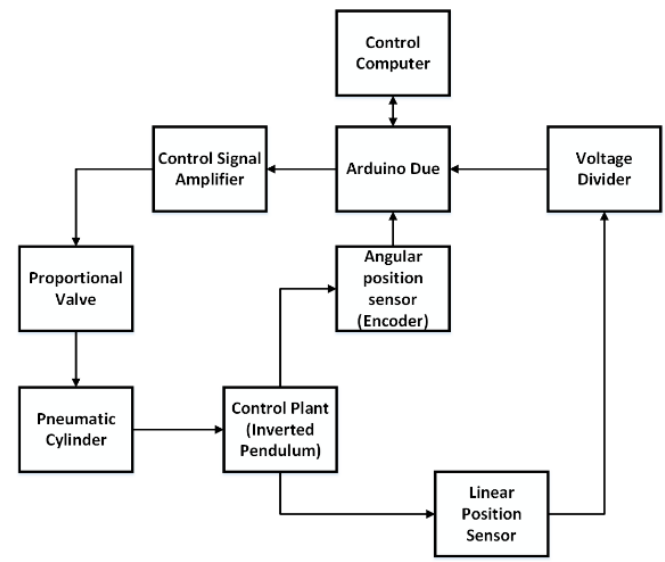

Fig. 10. Signals flow on the test rig

Tab. 1. System parameters

\begin{tabular}{|c|c|c|c|}
\hline & Parameter value & & Parameter value \\
\hline \multirow{4}{*}{$\begin{array}{l}\text { Long } \\
\text { pendulum } \\
\text { without } \\
\text { additional } \\
\text { load }\end{array}$} & $m=32 \mathrm{~g}$ & \multirow{4}{*}{$\begin{array}{l}\text { Long } \\
\text { pendulum } \\
\text { with addi- } \\
\text { tional load }\end{array}$} & $m=37 \mathrm{~g}$ \\
\hline & $l=215 \mathrm{~mm}$ & & $l=215 \mathrm{~mm}$ \\
\hline & $I=0,002 \mathrm{kgm}^{2}$ & & $I=0,0029 \mathrm{kgm}^{2}$ \\
\hline & $b_{p}=0,013 \frac{\mathrm{Nms}}{\mathrm{rad}}$ & & $b_{p}=0,009 \frac{\mathrm{Nms}}{\mathrm{rad}}$ \\
\hline \multirow{4}{*}{$\begin{array}{l}\text { Short } \\
\text { pendulum } \\
\text { without } \\
\text { additional } \\
\text { load }\end{array}$} & $m=26 g$ & \multirow{4}{*}{$\begin{array}{l}\text { Short } \\
\text { pendulum } \\
\text { with addi- } \\
\text { tional load }\end{array}$} & $m=31 \mathrm{~g}$ \\
\hline & $l=175 \mathrm{~mm}$ & & $l=175 \mathrm{~mm}$ \\
\hline & $I=0,0011 \mathrm{kgm}^{2}$ & & $I=0,0016 \mathrm{kgm}^{2}$ \\
\hline & $b_{p}=0,018 \frac{\mathrm{Nms}}{\mathrm{rad}}$ & & $b_{p}=0,015 \frac{\mathrm{Nms}}{\mathrm{rad}}$ \\
\hline \multicolumn{2}{|c|}{$M=2,7 \mathrm{~kg}$} & $81 \frac{m}{s^{2}}$ & $b=65 \frac{N s}{m}$ \\
\hline
\end{tabular}
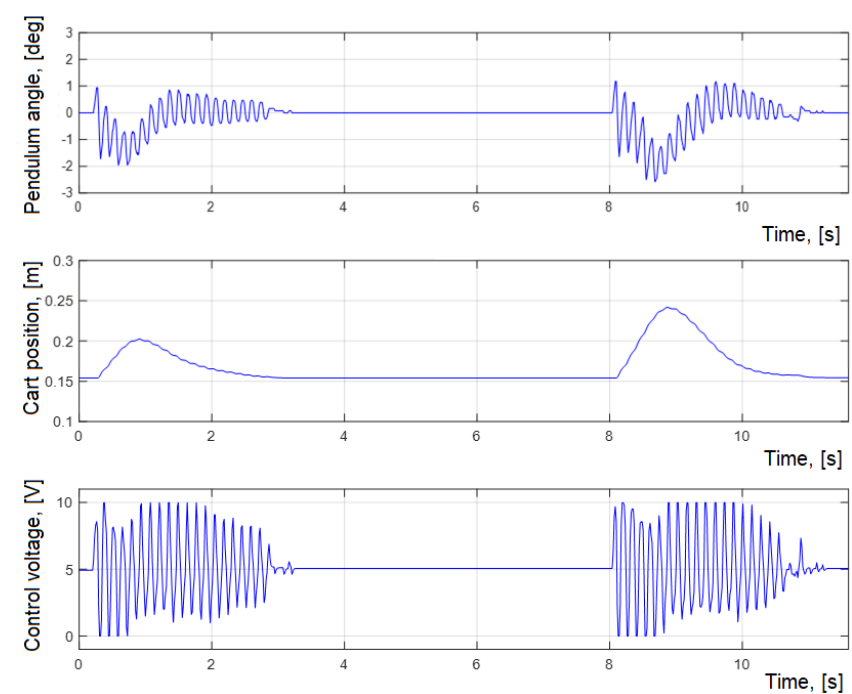

Fig. 11. Experimental results for long pendulum without additional load (external disturbance system response)
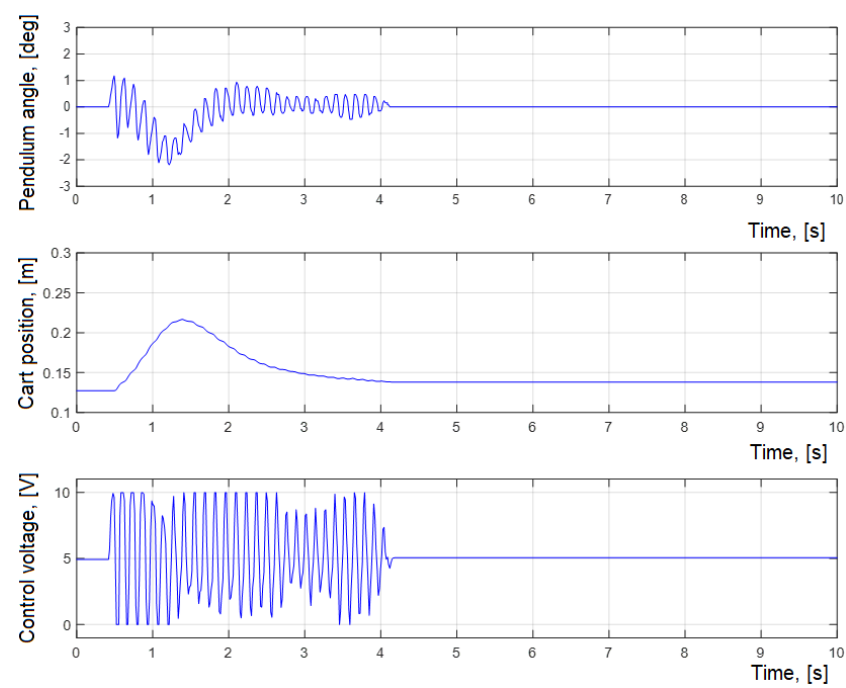

Fig. 12. Experimental results for long pendulum with additional load (external disturbance system response)
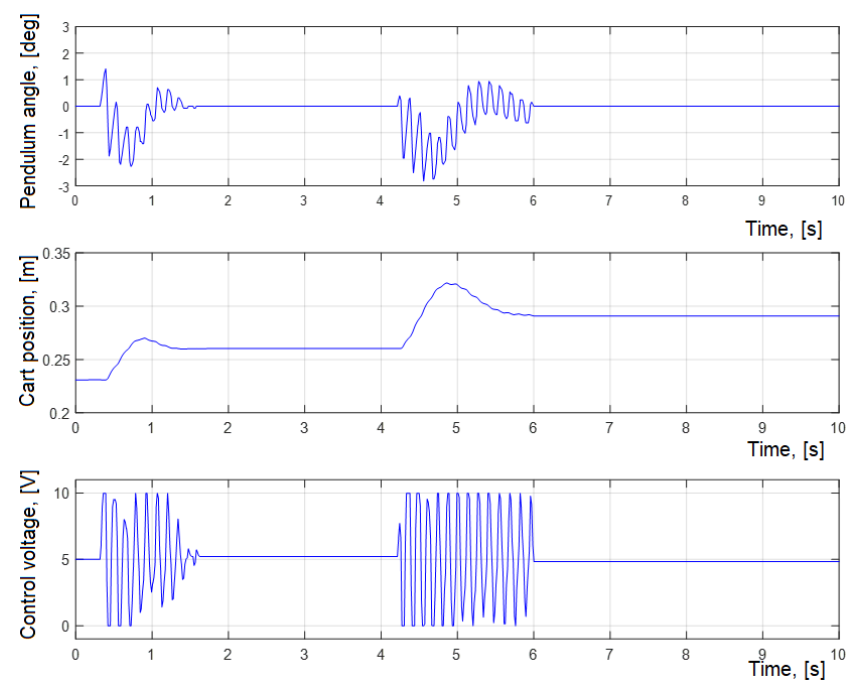

Fig. 13. Experimental results for short pendulum without additional load (external disturbance system response)
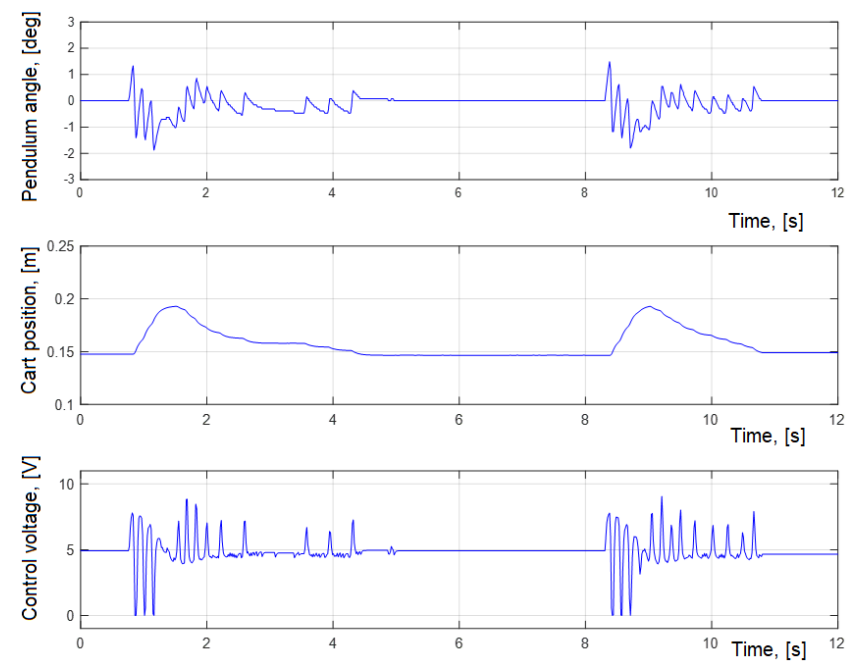

Fig. 14. Experimental results for short pendulum with additional load (external disturbance system response) 

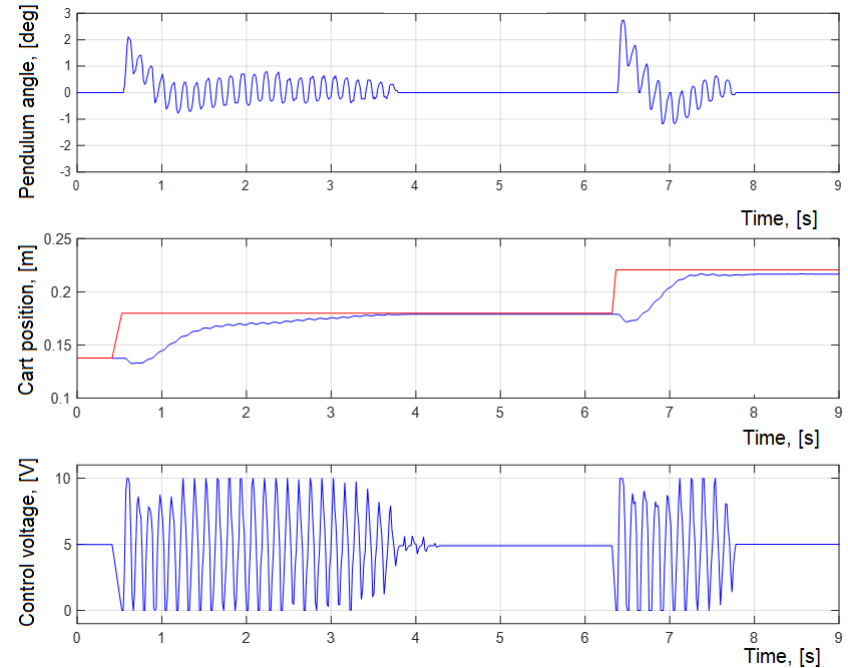

Fig. 15. Experimental results for long pendulum without additional load (step system response)
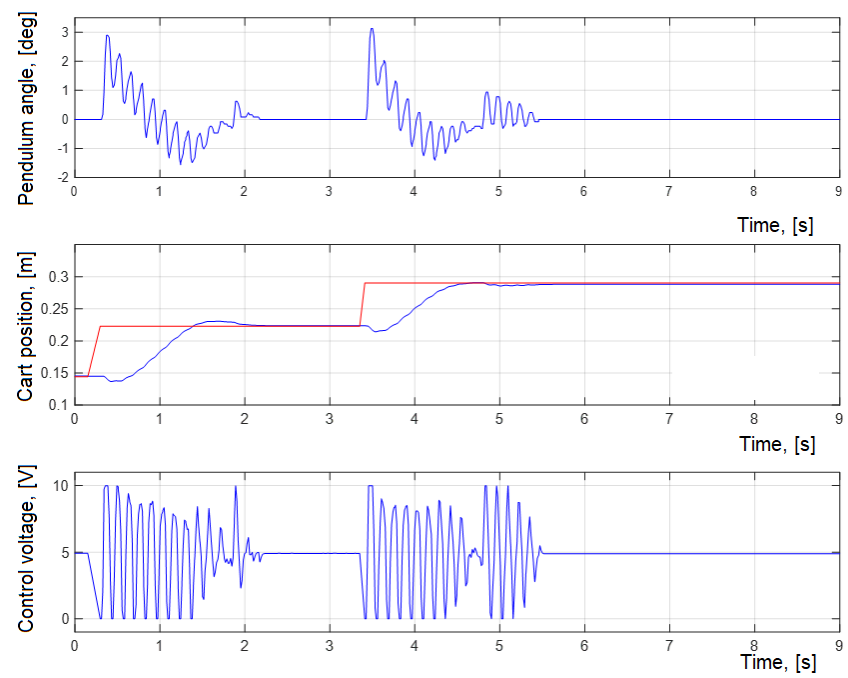

Fig. 16. Experimental results for long pendulum with additional load (step system response)
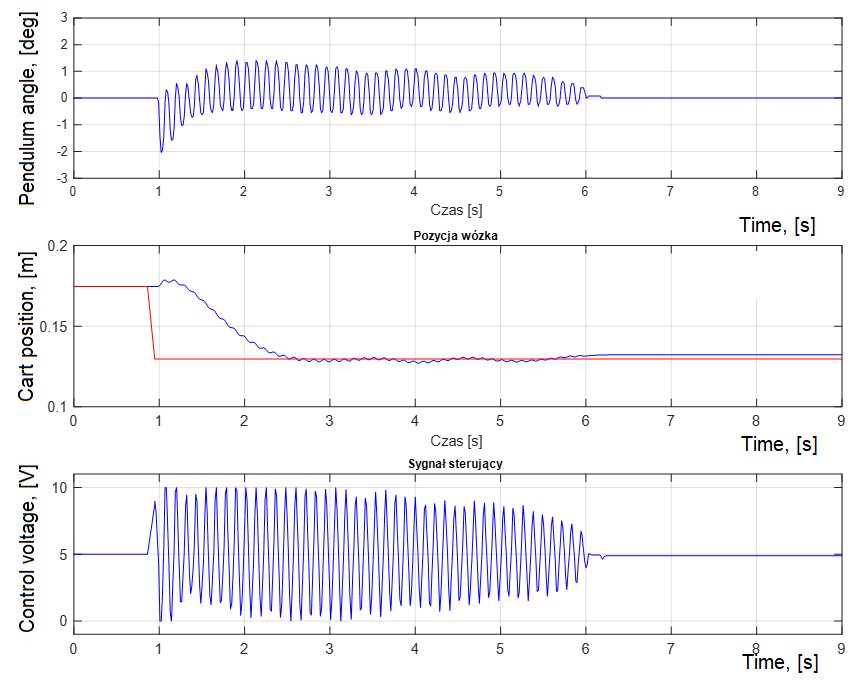

Fig. 17. Experimental results for short pendulum without additional load (step system response)
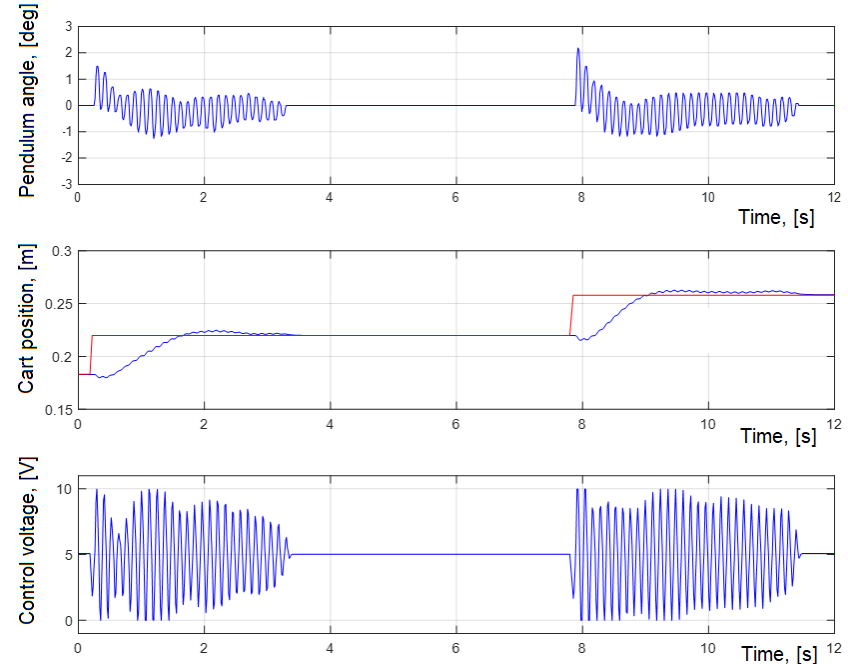

Fig. 18. Experimental results for short pendulum with additional load (step system response)

Next part of the experiment was step response by changing cart position. Fig. 15-18 present how system reacts to this kind of disturbance. The moment after cart set position changes, a pendulum is oscillating around its top vertical position, and at the same time, the cart is moving to the desired location. Also, this experiment resulted in average 3 seconds settling time and maximal deflection angle around $3^{\circ}$.

In Tab. 2, all the obtained results from the conducted experiments are shown. It contains setting times for external disturbance and step responses, maximal deflections and evolving error values for all tests.

Tab. 2. Control quality parameters

\begin{tabular}{|c|c|c|c|c|}
\hline & $\begin{array}{c}\text { Long } \\
\text { pendulum } \\
\text { without } \\
\text { additional } \\
\text { load }\end{array}$ & $\begin{array}{c}\text { Long } \\
\text { pendulum } \\
\text { with } \\
\text { additional } \\
\text { load }\end{array}$ & $\begin{array}{c}\text { Short } \\
\text { pendulum } \\
\text { without } \\
\text { additional } \\
\text { load }\end{array}$ & $\begin{array}{c}\text { Short } \\
\text { pendulum } \\
\text { with } \\
\text { additional } \\
\text { load }\end{array}$ \\
\hline $\begin{array}{c}\text { Setting time } \\
\text { (disturbance), [s] }\end{array}$ & 3,12 & 3,84 & 1,58 & 2,25 \\
\hline $\begin{array}{c}\text { Setting time (step } \\
\text { response), [s] }\end{array}$ & 3,41 & 2,14 & 5,67 & 4,02 \\
\hline $\begin{array}{c}\text { Maximal deflec- } \\
\text { tion, [ }{ }^{\circ} \text { ] }\end{array}$ & 3,05 & 2,83 & 3,36 & 3,69 \\
\hline Error, [cm] & 0,16 & 0,29 & 0,31 & 0,17 \\
\hline
\end{tabular}

\section{CONCLUSIONS}

The main purpose of the controlling inverted pendulum with pneumatic actuator was achieved. Difficulties during the development applied mainly to the programming part. One of them was reading pendulum angle using Simulink environment. The significant advantage of Arduino microcontroller is the possibility to control the inverted pendulum without a PC and any additional software.

The presented solution brings opportunity to research pneumatic drives in closed loop systems and thanks to that, the area of their application it can be broaden. Developed control algorithm can be successfully and easily adapted for inverted pendulum 
system with electric drive. Simultaneous use of MATLAB and microcontrollers allow relatively convenient verification of calculations without knowledge and deep analyse of $C$ code. Developed amplifying device makes Arduino Due microcontroller much more applicable in automation industry. During the experiments, it was observed that cylinder mechanical friction is mainly responsible for pulling effect at the time of pendulum stabilization. Another big advantage of Arduino microcontroller is major cost reduction in comparison with the building control system based on DAQ cards. Pneumatically actuated inverted pendulum system would be much more robust if at least twice as long cylinder and bigger, heavier pendulum were used.

\section{REFERENCES}

1. Ahangar-Asr H., Teshnehlab M., Mansouri M., Pazoki A. R. (2011), A Hybrid Strategy for the Control of Rotary Inverted Pendulum, International Conference on Electrical and Control Engineering (ICECE), 16-18 September, Yichang, China, 56565659.

2. Astrom K. J., Furuta K. (2000), Swing up a pendulum by energy control, Automatica, Vol. 36, No. 2, 287-295.

3. Avago Technologies (2006), AEDS-962x for 150 LPI Ultra Small Optical Encoder Modules, May.

4. Beater P. (2007), Pneumatic Drives, System Design, Modelling and Control, Springer.

5. Boubaker 0. (2012), The Inverted Pendulum: A Fundamental Benchmark in Control Theory and Robotics, IEEE International Conference on Education and e-Learning Innovations, Jul.

6. Boubaker 0. (2013), The Inverted Pendulum Benchmark in Nonlinear Control Theory: A Survey, International Journal of Advanced Robotic Systems, Vol. 10, 233:2013.

7. Bryson A. E., Ho Y. C. (1969), Applied Optimal Control, Blaisdell.

8. Hovingh A., Roon M. (2007), Design and Control of an Inverted Pendulum, Western Michigan University, Department of Aeronautical and Mechanical Engineering

9. Hui L., Min Z., Chen G. (2016), Cloud-Model PID Control of Double Inverted Pendulum Based on Information Fusion, 35th Chinese Control Conference, Jul. 27-29.
10. MathWorks (2017), Matlab Control System Toolbox User's Guide.

11. Moore M. L., Musacchio J. T., Passino K. M. (2001), Genetic adaptive control for an inverted wedge: experiments and comparative analyses, Engineering Applications of Artifcial Intelligence, Vol. 14, $1-14$.

12. Ozbek N. S., Efe M. O. (2010), "Swing up and Stabilization Control Experiments for a Rotary Inverted Pendulum - An Educational Comparison", International Conference on Systems Man and Cybernetics (SMC), 10-13 October, Istanbul, Turkey, 2226-2231.

13. Prasad L. B., Tyagi B., Gupta H. O. (2014), Optimal Control of Nonlinear Inverted Pendulum System Using PID Controller and LQR Performance Analysis Without and With Disturbance Input, International Journal of Automation and Computing 11(6), Dec., 661670.

14. Sang Y., Fan Y., Liu B. (2011), Double Inverted Pendulum Control Based on Three-loop PID and Improved BP Neural Network, Second International Conference on Digital Manufacturing and Automation (ICDMA), 5-7 August, Zhangjiajie, Hunan, China, 456-459.

15. Uszynski S., Ambroziak L., Kondratiuk M., Kulesza Z. (2018), Air Consumption Analysis in Compressed Air Powered Vehicles, 23rd International Conference on Methods and Models in Automation \& Robotics, MMAR 2018 8486124, 837-842.

16. Wang H., Chamroo A., Vasseur C., Koncar V. (2008), Stabilization of a 2-DOF Inverted Pendulum by a Low Cost Visual Feedback, American Control Conference, Seattle, 11-13 Jun.

17. White W. N., Fales R. C. (1999), Control of a Double Inverted Pendulum with Hydraulic Actuation: A Case Study. American Control Conference, San Diego, Jun

18. Zhangn X. L., Dai J. H., Cheng Y. T., Hao S., Li J. H. (2017) Nonlinear control of triple inverted pendulum based on T-S cloud inference network, Control And Decision Conference (CCDC), 28-30 May, Chongqing, China, 3290-3295.

19. Zhijun L., Chenguang Y., Liping F. (2013), Advanced Control of Wheeled Inverted Pendulum Systems, Springer.

The research work has been carried out in the framework of work No. WZ/WM-IIM/1/2019 and financed from the funds for science by the Polish Ministry of Science and Higher Education. 